\title{
LA CARGA DE LA PRUEBA EN PROCEDIMIENTOS DE CIRUGÍA PLÁSTICA Y RECONSTRUCTIVA ${ }^{1}$
}

\section{THE BURDEN OF PROOF IN THE PROCEDURES RELATED TO PLASTIC AND \\ RECONSTRUCTIVE SURGERY}

Carina Gómez Fröde

Directora General de Arbitraje en la CONAMED. Mestre y doctora en Derecho. México. E-mail: freude.carina@gmail.com

Para mi querido y admirado Maestro, Dr. José Ovalle Favela, brillante procesalista mexicano con mi infinita gratitud.

RESUMEN: El artículo aborda la teoría de la carga de la prueba en los procedimientos de cirugía plástica y reparadora, explicando en qué consistiría la teoría, su contextualización en el sistema legal mexicano y cómo se aplicaría a los procedimientos analizados.

PALABRAS-CLAVE: Carga de la prueba; Sistema legal mexicano; Cirugía plástica y reparadora.

\begin{abstract}
This paper deals with the theory of the burden of proof in plastic and restorative surgery procedures, explaining what the theory would consist of, its contextualization in the Mexican legal system and how it would apply to the procedures analyzed.
\end{abstract}

KEY WORDS: Burden of proof; Mexican legal system; Plasctic and Restorative Surgery.

\footnotetext{
${ }^{1}$ Artigo recebido em 11/08/2019, sob dispensa de revisão.
} 
SUMARIO.- I.- La carga de la prueba en general. II.- La carga dinámica de la prueba en Colombia. III.- La carga de la prueba en materia médica en México. IV.- La carga de la prueba en casos de cirugía plástica y reconstructiva. 1.-Mastopexia y abdominoplastía,2.Cambio de implantes.

\section{I.- LA CARGA DE LA PRUEBA EN GENERAL}

Para el Dr. José Ovalle Favela, la carga de la prueba (quien prueba) es la situación jurídica en que la ley coloca a cada una de las partes, consistente en el imperativo de probar determinados hechos en su propio interés, de tal modo que si no se cumple con ese imperativo se ubicarán en una situación de desventaja, respecto de la sentencia que se espera con arreglo a derecho (es decir, en una perspectiva de sentencia desfavorable. De acuerdo con la terminología de Goldschmidt); y en caso de que cumplan con dicha carga, se colocarán en situación de ventaja respecto de la sentencia que se espera con arreglo a derecho (en una expectativa, según Goldschmidt). ${ }^{2}$

Recordemos que Goldschmidt sostuvo que en proceso no surgen derechos ni obligaciones, ni se establecen relaciones jurídicas entre las partes y el juzgador; sino que éste se desenvuelve en una serie de situaciones jurídicas. Las partes tienen cargas procesales y si no se cumplen con éstas será en su propio perjuicio, precisamente por no haber atendido la carga procesal. Tal es la carga que tiene el demandado de dar contestación a la demanda, de desahogar una prevención, de probar los hechos en los que funde su pretensión o su resistencia, etcétera. La regla general es que el que afirma es el que tendrá la carga de la prueba. Las partes asumen la carga de la prueba de los hechos constitutivos de sus pretensiones. El que niega sólo estará obligado a probar (la reversión de la carga de la prueba) cuando la negación envuelva una afirmación, cuando se desconozca la presunción legal que tenga en su favor el colitigante, cuando se desconozca la capacidad o cuando la negativa fuere elemento constitutivo de la acción. ${ }^{3}$

${ }^{2}$ Ovalle Favela, José, Teoría General del Proceso, México, Oxford University Press, 7 a Edición, 2016,p.347

${ }^{3}$ Artículos 281 y 282 del Código de Procedimientos Civiles del Distrito Federal. 
Sin embargo, Ovalle formula una crítica fundamental a la teoría de Goldschmidt ${ }^{4}$, pues señala que éste contempla al proceso como un mero hecho y no como un fenómeno jurídico. Dice Ovalle la ha calificado como una "limitada perspectiva fáctica", cuyo se encuentra en la confusión que el autor judío-alemán hace de los derechos sustantivos o materiales controvertidos y de los derechos y obligaciones que se establecen con motivo del proceso. Ovalle afirma que si bien es cierto que, una vez que las partes acuden al proceso, los derechos materiales controvertidos quedan en estado de incertidumbre y sujetos a las contingencias del proceso, también lo es que, este estado de incertidumbre no afecta los derechos y obligaciones, así como los deberes, que corresponden a las partes y al juzgador dentro del proceso; es decir, no afecta los derechos, obligaciones y deberes de carácter procesal. Es decir para Ovalle el actor sí tiene el derecho de acción, el demandado sí tiene el derecho de excepcionarse, ambos también tienen el derecho de que el juez resuelva el litigio planteado y a su vez, el juez tiene el deber de resolver dicho litigio. La Suprema Corte de Justicia de la Nación ha sostenido precisamente este criterio fundamental:

Época: Décima Época Registro: 2014020 Instancia: Tribunales Colegiados de Circuito Tipo de Tesis: Jurisprudencia Fuente: Gaceta del Semanario Judicial de la Federación Libro 40, Marzo de 2017, Tomo IV Materia(s): Constitucional, Común Tesis: XI.1o.A.T. J/12 (10a.) Página: 2368

CARGA DE LA PRUEBA Y DERECHO A PROBAR. SUS DIFERENCIAS. No debe confundirse la oportunidad de ofrecer y desahogar pruebas, atinente a la defensa, con la carga probatoria, si se tiene en cuenta que la primera constituye un derecho -a probar- y la segunda es un deber procesal; asimismo, el derecho a probar es de naturaleza constitucional, en tanto el débito procesal es de naturaleza procesal e, incluso, es posterior al derecho fundamental de mérito, o sea, el derecho a probar es anterior y de entidad superior a la obligación procesal, siendo que derecho y obligación no son sinónimos dado que uno se ejerce en el procedimiento, tanto postulatorio como probatorio, mientras que la otra es objeto de examen por el juzgador hasta la sentencia o laudo; sin que deba validarse una decisión jurisdiccional de denegación de pruebas cuando suponga la imposición de un formulismo obstaculizador, o contrario a la

${ }^{4}$ Ovalle Favela, José, op.cit, p. 202 
Rio de Janeiro. Ano 13. Volume 20. Número 3. Setembro a Dezembro de 2019

Periódico Quadrimestral da Pós-Graduação Stricto Sensu em Direito Processual da UERJ

Patrono: José Carlos Barbosa Moreira (in mem.). ISSN 1982-7636. pp. 75-101

www.redp.uerj.br

efectividad del derecho a la prueba, ni subordinar la eficacia de ese derecho fundamental a otro tipo de intereses, como los de economía procesal, expeditez de los juicios, o el prejuzgamiento de la carga probatoria, cuando su decisión no es propia de la resolución que acepta pruebas sino de la sentencia o laudo, lo que significa que es ilegal anticipar la carga de la prueba a una de las partes al momento de decidir sobre su admisión o no, ni invocar algún otro formalismo que impida conocer el resultado de una prueba en detrimento del derecho a probar, que es uno de los que conforman el derecho humano al debido proceso; luego, si el derecho a probar es un derecho constitucional que atribuye a la persona el poder tanto de ejercerlo, como de reclamar su debida protección, entonces su constitucionalización obedece a la relevancia procesal que adquiere la actividad probatoria, en la medida en que determina a las partes cuándo y cómo pueden probar los hechos del debate jurisdiccional, vinculando a todo juzgador a su observancia. Lo anterior, porque en la interpretación de las normas probatorias también es procedente la que permita la máxima actividad probatoria de las partes, prefiriendo, inclusive, el exceso en la admisión de pruebas, a la de una interpretación restrictiva, por cuanto en aquélla subyace la idea de aproximar, y hasta de hacer coincidir la verdad histórica con la verdad que habrá de declararse en la sentencia, partiendo de la base de que la verdad es un derecho humano cuya restricción necesariamente debe justificarse y, por ende, la norma probatoria ha de interpretarse conforme al artículo 14 de la Constitución Política de los Estados Unidos Mexicanos, en lo concerniente al derecho humano al debido proceso.

Sin embargo, Ovalle reconoce que la teoría de Goldschmidt puso de manifiesto que en relación a ciertos actos del proceso ${ }^{5}$, las partes más que obligaciones tienen verdaderas cargas procesales.

En el mundo del proceso, la prueba es fundamental, ya que estando destinada a producirle certeza al juez, no se puede prescindir de ella. La prueba tiene una función social, una función humana individual y una función jurídica. El poder-deber de decretar pruebas de oficio para averiguar la verdad de los hechos controvertidos, si bien es una ideología, ha surgido de la necesidad de poder mostrar a la población algún criterio atendible sobre el

${ }^{5}$ Ibidem,p.203. 
Rio de Janeiro. Ano 13. Volume 20. Número 3. Setembro a Dezembro de 2019

Periódico Quadrimestral da Pós-Graduação Stricto Sensu em Direito Processual da UERJ

Patrono: José Carlos Barbosa Moreira (in mem.). ISSN 1982-7636. pp. 75-101

www.redp.uerj.br

cual se pueda afirmar que la decisión es justa, y uno de esos ingredientes es que se construya sobre la verdad. ${ }^{6}$

El Profesor colombiano Jairo Parra Quijano afirma que:

...no es la carga una obligación ni un deber, por no existir sujeto o entidad legitimada

para exigir su cumplimiento. Tiene necesidad que aparezca probado el hecho la parte

que soporta la carga, pero su prueba puede lograrse por actividad oficiosa del juez o la contraparte. ${ }^{7}$

Las reglas sobre la carga de la prueba apoyan al juez a formarse un juicio afirmativo o negativo sobre la procedencia o no de la pretensión del actor, no obstante las incertidumbres con respecto a las circunstancias de hecho. La esencia y el valor de las normas sobre la carga de la prueba consisten en esta instrucción otorgada al juez en relación al contenido de la sentencia que deberá pronunciar. Leo Rosenberg afirmaba que la decisión debía dictarse en contra de la parte sobre la que recae la carga de la prueba con respecto a la afirmación de hecho no aclarada y probada. ${ }^{8}$

Para Devis Echandía ${ }^{9}$ la carga de la prueba no significa que la parte sobre quien recae deba ser necesariamente quien presente o solicite la prueba del hecho que fundamenta su pretensión o excepción sino que señala apenas a quién interesa la demostración de ese hecho en el proceso. Se exige que aparezca la prueba, más no importa quién la aduzca. Devis consideró incorrecto decir que la carga de la prueba determina quién debe probar cada hecho, pues únicamente señala quién tiene interés jurídico en que resulte probado, porque se perjudica o sufre la consecuencia desfavorable de su falta de prueba; sólo cuando no aparece ésta, corresponde determinar la parte que debía evitar su omisión. Es decir: Indica a quién corresponde evitar que falte la prueba de cierto hecho, si pretende obtener una decisión favorable basada en él, pero si el juez o la contraparte la suministran, queda cumplido el interés de quien era sujeto de tal carga y satisfecha ésta. Si es un hecho exento de prueba, no existe carga de probarla.

\footnotetext{
${ }^{6}$ Parra Quijano, Jairo, Manual de derecho probatorio, Bogotá, Ediciones Librería del Profesional, 1986, p.3 y Racionalidad e Ideología en las pruebas de oficio, Temis, Bogotá, 2004, p. IX

${ }^{7}$ Ibidem,p. 242

${ }^{8}$ Rosenberg, Leo, La carga de la prueba, Montevideo, B de F, 2002, p.7

${ }_{9}^{9}$ Devis Echandía, Hernando, Compendio de la prueba judicial, Argentina, Rubinzal-Culzoni Editores, 2007,p.198
} 


\section{II.- LA CARGA DINÁMICA DE LA PRUEBA EN COLOMBIA}

Con el ánimo de dejar atrás las reglas férreas e inflexibles de origen romano que han caracterizado al manejo judicial de la carga de la prueba, como: incumbe probar al actor, cuando el demandado opone excepciones debe probar y si el actor no prueba se absuelve al demandado en el Código General del Proceso colombiano se incluyeron las siguientes reglas:

Artículo 167. Carga de la prueba. Incumbe a las partes probar el supuesto de hecho de las normas que consagran el efecto jurídico que ellas persiguen. No obstante, según las particularidades del caso, el juez podrá, de oficio o a petición de parte, distribuir la carga al decretar las pruebas, durante su práctica o en cualquier momento del proceso antes de fallar, exigiendo probar determinado hecho a la parte que se encuentre en una situación más favorable para aportar las evidencias o esclarecer los hechos controvertidos. La parte se considerará en mejor posición para probar en virtud de su cercanía con el material probatorio, por tener en su poder el objeto de prueba, por circunstancias técnicas especiales, por haber intervenido directamente en los hechos que dieron lugar al litigio, o por el estado de indefensión o de incapacidad en la cual se encuentre la contraparte, entre otras circunstancias similares. Cuando el juez adopte esta decisión, que será susceptible de recurso, otorgará a la parte correspondiente el término necesario para aportar o solicitar la respectiva prueba, la cual se someterá a las reglas de contradicción previstas en este código. ${ }^{10}$

Para Peyrano ${ }^{11}$ más allá del carácter de actor o demandado, en determinados supuestos la carga de la prueba recae sobre ambas partes, en especial sobre aquella que se encuentre en mejores condiciones para producirla. Esta teoría no desconoce las reglas clásicas de la carga de la prueba, sino que trata de complementarla o perfeccionarla, flexibilizando su aplicación en todos aquellos supuestos en que quien debía probar según la regla tradicional se veía imposibilitado de hacerlo por motivos completamente ajenos a su voluntad.

\footnotetext{
${ }^{10} \mathrm{http} / / / \mathrm{www}$. icdp.org.co/descargas/cgp/CodigoGeneralDelProceso12Julio2012.pdf

${ }^{11}$ Peyrano, Jorge Walter, et al. Cargas probatorias dinámicas, Argentina, Rubinzal-Culzoni Editores, 2008,p.60
} 
Rio de Janeiro. Ano 13. Volume 20. Número 3. Setembro a Dezembro de 2019

Periódico Quadrimestral da Pós-Graduação Stricto Sensu em Direito Processual da UERJ

Patrono: José Carlos Barbosa Moreira (in mem.). ISSN 1982-7636. pp. 75-101

www.redp.uerj.br

El legislador colombiano, a través del artículo 167 del Código General del Proceso, anunció aquellos casos en que una parte se considera en mejor posición para probar concluyendo sin mayores precisiones, que una parte está en mejor posición para probar:

- En virtud de su cercanía con el material probatorio

- Por tener en su poder el objeto de prueba

- Por circunstancias técnicas especiales

- Por haber intervenido directamente en los hechos que dieron lugar al litigio

- Por el estado de indefensión o de incapacidad en la cual se encuentre la contraparte

- Entre otras circunstancias similares

Para Díaz-Restrepo, estas son las hipótesis que conforme a la definición legal del artículo 167 integran el concepto de mejor posición para probar. En alguna de ellas, se debe encontrar respecto de la prueba, la parte a la que se le grave, con la responsabilidad de desahogarla, a través de la distribución hecha por el juez. La verificación de la mejor posición para probar habilita al juez para hacer uso de su facultad de distribución de la carga de la prueba. Como condición exigida, para que proceda la aplicación de la carga de la prueba en su modalidad dinámica, produce que ésta sea una regla de aplicación excepcional sujeta a la verificación en el caso concreto de alguna de las hipótesis de hecho que dan lugar a que una de las partes sea considerada por el juez en mejor posición para desahogar la prueba. ${ }^{12}$ Sin embargo, Díaz-Restrepo se pregunta si la aplicación del dinamismo de la carga de la prueba menoscaba la igualdad procesal y ante dicha preocupación propone una mayor precisión normativa. El camino a seguir es la creación de principios y pautas que impongan la satisfacción de un estándar de certeza, en la medida que posea justificación suficiente y objetiva, en el sentido de que en cada caso concreto se verifique que efectivamente existe una situación de desequilibrio entre las partes.

La Corte Constitucional Colombiana ${ }^{13}$ resolvió en la Sentencia T-352/97 que los requisitos para la justificación de un tratamiento judicial diferenciado en virtud de uno de los criterios constitucionalmente "sospechosos" supere el juicio de igualdad y la presunción

\footnotetext{
${ }^{12}$ Díaz-Restrepo, Juan Carlos, La carga dinámica de la prueba como modalidad de carga probatoria aplicada en el ordenamiento jurídico colombiano. Vulneración a la igualdad constitucional. Entramado. Enero.Julio,2016 vol.12,noI, p. 211. http://www.scielo.org.co/pdf/entra/v12n1/v12n1a14.pdf

${ }^{13} \mathrm{http} / / / \mathrm{www}$. corteconstitucional.gov.co/
} 
de inconstitucionalidad que la cobija, se requiere que se verifiquen los siguientes requisitos: (1) que persiga un objetivo constitucionalmente imperioso; (2) que obren datos suficientes para afirmar que resulta idónea para garantizar la finalidad perseguida; (3) que es indispensable para alcanzar tal propósito; (4) que el beneficio que se busca obtener es mayor que el daño que causa; y (5) que el trato diferenciado se ajusta al grado de la diferencia que existe entre las personas o grupos de personas involucrados. Si una medida de la naturaleza de la que se estudia, no cumple alguna de estas condiciones, compromete el derecho a la igualdad.

Por su parte, Juliana Pérez Restrepo ${ }^{14}$ afirma que desde la emisión de la sentencia del 31 de agosto de 2006, en Colombia se resquebrajó la carga dinámica de la prueba como modalidad de carga procesal para decidir los casos de responsabilidad administrativa por la actividad médica, considerándose que en adelante, las decisiones se tomarían con fundamento en la regla de prueba de falla probada, tomando especial relevancia la prueba indiciaria.

Se excluyó entonces, la carga dinámica de la prueba, toda vez que se advirtió que el acogimiento de esa regla probatoria traía mayores dificultades que soluciones, a su vez que, con la aplicación de la falla presunta en determinados casos, se marginaban del debate probatorio asuntos muy relevantes. Se volvió, por ende, a la exigencia de la prueba de la falla del servicio por parte del actor como regla general. Igualmente, en esta sentencia se plantea que cuando resultare imposible esperar certeza o exactitud del vínculo causal, "el juez puede contentarse con la probabilidad de su existencia". Se han recogido, pues, las reglas jurisprudenciales de presunción de falla médica o de la distribución de las cargas probatorias, para acoger nuevamente la regla general de falla probada, donde la prueba indiciaria cobra particular importancia, en especial para la demostración del nexo causal entre la actividad médica y el daño. Se aduce que con este criterio, además de ajustarse a la normatividad vigente, el proceso resulta más equitativo.

\footnotetext{
${ }^{14}$ Pérez Restrepo, Juliana, La carga dinámica de la prueba en la responsabilidad administrativa por la actividad médica-decaimiento de su aplicabilidad. Universidad de Antioquía, Medellín. Colombia, Vol. LXVIII.No.152,diciembre 2011, http://bibliotecadigital.udea.edu.co/bitstream/10495/2374/1/PerezJuliana_2011_CargaResponsabilidadAdmin istrativa.pdf
} 
La Sala Civil de la Corte Suprema de Justicia colombiana es la competente para dirimir los conflictos derivados de la mala praxis médica. En principio, las partes dentro del proceso deben de aplicar la teoría de la auto-responsabilidad en materia probatoria. Sin embargo se comprobó que esa teoría lesionaba los intereses de la víctima del daño médico, porque le correspondería al paciente probar la culpa del deudor de la obligación, en este caso el prestador del servicio médico, prestador quien tiene los conocimientos médicos, técnicos y científicos para probar la ausencia de culpa, a través de las denominadas eximentes de responsabilidad en el ejercicio del derecho de acción en vía de contradicción. Lo observado por parte del juez de la causa es el comportamiento o conducta del demandado y no la actividad que genera riesgo en la prestación del servicio. José López Oliva ${ }^{15}$ ha propuesto que en los procesos de responsabilidad médica y sanitaria debe operar la denominada responsabilidad por culpa presunta, invirtiendo la carga de la prueba para que el prestador del servicio de salud, quien tiene los conocimientos inherentes a su actividad, sea quien deba probar la ausencia de culpa, incorporando la responsabilidad por culpa presunta.

\section{III.- LOS CRITERIOS JUDICIALES DE LA CARGA DE LA PRUEBA EN MATERIA MÉDICA EN MÉXICO.}

En los casos de responsabilidad civil en contra de los médicos privados, derivada de su negligencia, resulta excesivo establecer que el usuario del servicio de salud debe demostrar la mala práctica médica para que proceda la responsabilidad civil, pues no sólo llevaría la carga de ser víctima de la mala praxis o del acto que motivó el daño, sino que judicialmente sería revictimizado, al obligársele a probar una cuestión fuera de su alcance.

De acuerdo con el punto 5.4, de la Norma Oficial Mexicana NOM-004-SSA3-2012 ${ }^{16}$, Del expediente clínico, los expedientes clínicos son propiedad de la institución o del prestador de servicios médicos que los genera, cuando éste, no dependa de una institución, como ocurre en el particular.

Lo que cobra relevancia dado que la prueba idónea para demostrar el acto médico es el expediente clínico, como lo establece la tesis de jurisprudencia, aplicable por analogía y en

\footnotetext{
${ }^{15}$ López Oliva José, La carga de la prueba en procedimientos de cirugía plástica en Colombia, Barranquilla,Universidad Libre Seccional, Advocatus, Volúmen 13,No. 26: 41-58,2016p.56

${ }^{16} \mathrm{http} / / /$ dof.gob.mx/nota_detalle_popup.php?codigo=5272787
} 
lo conducente, número I.3o.C.788 C, sustentada por el Tercer Tribunal Colegiado en Materia Civil del Primer Circuito, que aparece en el Semanario Judicial de la Federación, Novena Época, tomo XXXI, abril de 2010, página: $2715,{ }^{17}$ cuyo contenido es el siguiente:

“CONTRATO DE SEGURO DE VIDA. LA COMPAÑ́́A ASEGURADORA DEBE ACREDITAR MEDIANTE PRUEBA IDÓNEA QUE EL ASEGURADO TENÍA PLENO CONOCIMIENTO DE QUE PADECÍA UNA ENFERMEDAD PREEXISTENTE Y QUE OMITIÓ DECLARARLO AL LLENAR EL CUESTIONARIO RESPECTIVO. Conforme a lo establecido en el artículo 47 de la Ley Sobre el Contrato de Seguro cualquier omisión o inexacta declaración de los hechos importantes que sean o deban ser conocidos en el momento de la celebración del contrato de seguro por parte del asegurado, facultará a la empresa aseguradora para considerar rescindido de pleno derecho el contrato, aunque no haya influido en la realización del siniestro; sin embargo tratándose de lo relativo a la información que se solicita dentro de los cuestionarios respectivos en cuanto a las enfermedades preexistentes del asegurado, debe tomarse en cuenta por un lado que es imputable a la aseguradora el hecho de que no realice las preguntas conducentes que la lleven a revelar que el asegurado tiene conocimiento de algún padecimiento y por otra parte en términos del artículo 1194 del Código de Comercio le corresponde acreditar la excepción consistente en que el asegurado tenía conocimiento del padecimiento y que omitió manifestarlo, sin que baste para acreditar tal conocimiento, que en el certificado médico que previamente se elabora para la expedición del certificado de defunción, se establezca como causas o antecedentes del fallecimiento del asegurado, que entre el inicio de la enfermedad y la muerte haya existido un intervalo de tiempo que sea anterior a la fecha en que el asegurado llenó el cuestionario anexo a la solicitud del seguro de vida, pues esa información y la que consta en el certificado de defunción en todo caso sólo acreditan la muerte y las causas del fallecimiento, pero no que el asegurado hubiera tenido conocimiento de ese padecimiento al momento de contratar, pues para ello se estima como prueba idónea el expediente clínico del mismo en el que conste algún estudio que se le hubiera practicado o algún tratamiento que haya llevado

${ }^{17}$ http://sjf.scjn.gob.mx/sjfsist/Documentos/Tesis/164/164822.pdf 
por virtud de esa enfermedad, por lo que al no demostrarse ese conocimiento pleno de la enfermedad, tampoco se acredita que hubiera omitido esa información al llenar el cuestionario correspondiente."

Los usuarios de los servicios de atención médica, así como sus familiares, están en una condición de desventaja, por lo que no se puede revertir la carga de la prueba al paciente, toda vez que la obligación de contar con el expediente clínico corresponde al hospital y al médico, y no al paciente. De ahí que el usuario de los servicios de salud privada, al estar en una posición de desventaja frente a la institución médica, no tiene la carga de la prueba. Sirve de apoyo, en lo conducente, la tesis de jurisprudencia número: 1a. CXVII/2015 (10a.), emitida por la Primera Sala de la Suprema Corte de Justicia de la Nación, Décima Época, publicada en la Gaceta del Semanario Judicial de la Federación, tomo: libro 16, marzo de 2015, tomo II, página: $1112^{18}$, que a la letra dice:

\section{“RESPONSABILIDAD CIVIL DE LOS HOSPITALES PRIVADOS DERIVADA} DE LA NEGLIGENCIA DE SUS MÉDICOS. CARGA DE LA PRUEBA. En los casos de responsabilidad civil de los hospitales privados, derivada de la negligencia de sus médicos, resulta excesivo establecer que el usuario del servicio de salud debe demostrar la relación laboral o profesional entre aquéllos y el hospital para que proceda la responsabilidad civil de ambos, pues no sólo llevaría la carga de ser víctima de la mala praxis o del acto que motivó el daño, sino que judicialmente sería revictimizado, al obligársele a probar una cuestión fuera de su alcance. En esas condiciones, los usuarios de los servicios de atención médica, así como sus familiares, están en una condición de desventaja por el desconocimiento del personal del hospital que tiene la calidad de empleado y la de independiente, pues no están enterados de las complejidades técnicas de los acuerdos contractuales y de empleo entre el hospital y el personal que opera ahí, al contrario del hospital, que sí tiene conocimiento y, además, decide cómo organizarse y representarse. De ahí que el usuario de los servicios de salud privada, al estar en una posición de desventaja frente a la institución médica, no tiene la carga de la prueba."

\footnotetext{
${ }^{18}$ https://sjf.scjn.gob.mx/sjfsist/Documentos/Tesis/2008/2008747.pdf
} 
En el mismo sentido, la tesis de jurisprudencia número: 1a. CCXXVII/2016 (10a.), sustentada por la Primera Sala de la Suprema Corte de Justicia de la Unión, publicada en el Semanario Judicial de la Federación, en la Décima Época, ${ }^{19}$ cuyo contenido es el siguiente:

\section{“RESPONSABILIDAD CIVIL EXTRACONTRACTUAL EN MATERIA} MÉDICO-SANITARIA. DISTRIBUCIÓN DE LA CARGA DE LA PRUEBA.

De conformidad con las pautas establecidas por la Primera Sala de la Suprema Corte de Justicia de la Nación al resolver la contradicción de tesis 93/2011, para acreditar la responsabilidad civil de los profesionistas médico-sanitarios ante una demanda en la que se alegue la existencia de un daño, a los profesionales referidos les corresponde probar su debida diligencia (el elemento de culpa), mientras que la demandante debe acreditar el resto de los elementos de la responsabilidad civil extracontractual: daño y nexo causal. En otras palabras, cuando una persona alegue que un profesional médico-sanitario o una institución hospitalaria le causó un daño por una indebida atención médico-sanitaria, se actualiza lo que se denomina una reinversión de la carga de la prueba a favor de la actora en el juicio, en la que a los profesionales médico-sanitarios o a la institución hospitalaria les corresponde acreditar su debida diligencia en la atención médica del paciente que sufrió el referido evento dañoso, en atención a los principios de facilidad y proximidad probatoria. La razón principal para optar por esta incidencia en las reglas estrictas de la carga de la prueba proviene de las circunstancias particulares en las que se desarrolla un caso de atención médica; por lo general, el conocimiento científico-técnico y las pruebas pertinentes para acreditar la debida diligencia o desacreditar la supuesta culpa o violación de un deber de cuidado las detentan los profesionales médico-sanitarios o las instituciones hospitalarias, por lo que exigir de una forma irrestricta que sea la actora la que demuestre por sí sola y sin lugar a dudas la negligencia en la atención médica podría provocar lo que en la doctrina se denomina como una carga probatoria diabólica. Esto es, lo que se busca es que ambas partes en el juicio participen

\footnotetext{
${ }^{19}$ https://sjf.scjn.gob.mx/sjfsist/Documentos/Tesis/2012/2012513.pdf
} 
Revista Eletrônica de Direito Processual - REDP.

Rio de Janeiro. Ano 13. Volume 20. Número 3. Setembro a Dezembro de 2019

Periódico Quadrimestral da Pós-Graduação Stricto Sensu em Direito Processual da UERJ

Patrono: José Carlos Barbosa Moreira (in mem.). ISSN 1982-7636. pp. 75-101

www.redp.uerj.br

activamente en él y que aporten los elementos de convicción necesarios para que el juzgador llegue a la verdad y estudie si se acreditan o no los elementos de la acción. Esta posición no conlleva a la existencia de una presunción de la culpa de los médicos o de la institución hospitalaria o el surgimiento de una responsabilidad objetiva, pues en materia de responsabilidad civil subjetiva derivada de la atención médica, la cual es caracterizada en términos generales como una actividad que da lugar a obligaciones de medios, no cabe la presunción automática de la culpa de las partes demandadas, sin que ello implique que ésta no pueda acreditarse a partir de algún tipo de presunciones (por ejemplo, indiciarias).

De igual forma, de manera analógica y en lo conducente, la tesis de jurisprudencia número: 1a. CXXXII/2012 (10a.), sustentada también por la Primera Sala del máximo tribunal de justicia del país, visible en el Semanario Judicial de la Federación y su Gaceta, Décima Época, libro XI, agosto de 2012, tomo 1, página: $498^{20}$, cuyo rubro y texto son los siguientes:

\section{“RESPONSABILIDAD PATRIMONIAL DEL ESTADO POR PRESTACIÓN} DEFICIENTE DEL SERVICIO DE SALUD PÚBLICO. LA CARGA DE LA PRUEBA DE DEBIDA DILIGENCIA RECAE EN EL PERSONAL MÉDICO. A pesar de que se ha determinado que en el caso de la responsabilidad patrimonial del Estado, es necesario probar el actuar irregular del Estado, es posible señalar al tiempo, que en los casos en que esta responsabilidad emana de la prestación de un servicio de salud deficiente, la prueba de la debida diligencia recae en las instituciones médicas del Estado, en atención al derecho de indemnización de la víctima. En efecto, debido a la dificultad que representa para la víctima probar el actuar irregular de los centros de salud, se posibilita un desplazamiento de la carga de la prueba para que sea la institución del Estado la que demuestre que el procedimiento médico se realizó de acuerdo a los cuidados establecidos en la normatividad de la materia y al deber de diligencia que le exige la profesión médica. Lo anterior se justifica de acuerdo con los principios de facilidad y proximidad probatoria, con base en los cuales debe satisfacer

\footnotetext{
${ }^{20}$ https://sjf.scjn.gob.mx/sjfsist/Documentos/Tesis/2001/2001476.pdf
} 
Rio de Janeiro. Ano 13. Volume 20. Número 3. Setembro a Dezembro de 2019

Periódico Quadrimestral da Pós-Graduação Stricto Sensu em Direito Processual da UERJ

Patrono: José Carlos Barbosa Moreira (in mem.). ISSN 1982-7636. pp. 75-101

www.redp.uerj.br

la carga de la prueba la parte que dispone de los medios de prueba o puede producirla

o aportarla al proceso a un menor coste para que pueda ser valorada por el juez."

Como se desprende del estudio realizado en la sentencia pronunciada por la Primera Sala de la Suprema Corte de Justicia de la Nación en el amparo directo 51/2013, derivado del ejercicio de la facultad de atracción 220/2013, dicha Sala se ha pronunciado en un par de ocasiones sobre las características de la carga de la prueba en los juicios de responsabilidad civil que derivan de hechos relacionados con una negligencia médica.

El primer precedente es la contradicción de tesis 93/2011, resuelta por unanimidad de votos el veintiséis de octubre de dos mil once, en la que estableció que dada la dificultad de que las personas que sufren el daño prueben el actuar negligente de los médicos, en el caso un anestesiólogo, y toda vez que estos profesionales y/o las instituciones de salud pueden acceder con mayor facilidad a los medios de prueba para demostrar su actuar diligente, puesto que tienen los conocimientos necesarios para determinar qué información puede ser relevante en el proceso y pueden acceder a dichos medios de prueba con mayor libertad que la persona afectada, se posibilita la reversión de la carga de la prueba para que sean estos últimos los que comprueben que su conducta fue diligente.

Posterior a la emisión de esta sentencia, la Primera Sala dio cuenta de este criterio en el amparo en revisión 584/2013, fallado el quince de noviembre de dos mil catorce. La materia de este amparo radicó, más que en cómo se acreditan o prueban los hechos que pueden dar origen a una responsabilidad civil por una negligente atención médica, en si un hospital privado puede o no ser considerado responsable por los actos negligentes llevados a cabo por médicos que ejercen su profesión en ese lugar, pero que no forman parte contractualmente de la institución hospitalaria.

La Sala llegó a una conclusión positiva y condenó al hospital demandado a responder de manera subsidiaria por el daño ocasionado por uno de los médicos demandados (cardiólogo del hospital), al habérsele considerado materialmente como uno de sus dependientes a pesar de la inexistencia de una relación contractual de trabajo, bajo la figura de la representación aparente. ${ }^{21}$

\footnotetext{
${ }^{21}$ Grayeb Cervantes, Antonio, El derecho humanos a la salud, la representación aparente y la responsabilidad en la prestación de servicios médicos particulares. México, Revista Conamed, Volúmen 24, Número 1, Enero.marzo, 2019,
} 
Existe una posición de disparidad frente a quienes manejan, desarrollan, y controlan los servicios de salud, situación en la que se ven vulnerados en sus derechos fundamentales ante la asimetría de poder entre el hospital y los usuarios, por la propia naturaleza de los servicios y por la complejidad de la medicina como profesión.

Por último, en sesión de cinco de agosto de dos mil quince, la citada Primera Sala resolvió los amparos directos 42/2012, 43/2012, 44/2012 y 45/2012, los cuales tenían como objeto una demanda de responsabilidad civil extracontractual en contra de varios médicos y del Instituto Nacional de Rehabilitación por el daño ocasionado a una paciente tras la colocación de una prótesis de cadera que afectó el nervio ciático. En la sentencia se hizo alusión a los referidos criterios de carga de la prueba en materia de responsabilidad médica y se determinó que los médicos actuaron negligentemente, precisamente porque no probaron en el juicio su debida diligencia en cuanto a la atención en específico de la paciente que sufrió el daño; es decir, no aportaron elementos de prueba suficientes para evidenciar que se le dio la debida atención médica a la paciente respecto a su situación particular, tampoco se le informó de los posibles riesgos de la operación y en la misma se le lesionó el nervio ciático, lo cual acreditó una conducta culposa por parte de los médicos.

Valorados y aplicados dichos precedentes, se llegó a la conclusión de que para efectos de acreditar la responsabilidad civil de los profesionistas médicos-sanitarios en todas las etapas del acto médico debe seguirse la misma línea de razonamiento que en la aludida contradicción de tesis 93/2011 y en los amparos directos 42/2012, 43/2012, 44/2012 y $45 / 2012$.

Ante una demanda en la que se alegue la existencia de un daño motivado por una atención médico-sanitario, a los profesionales médico-sanitarios le corresponde probar su debida diligencia (el elemento de culpa). Así, cuando una persona alegue que un profesional médico-sanitario o institución hospitalaria le causó un daño por una indebida atención médica-sanitaria, se actualiza lo que la Suprema Corte denomina como una reinversión de la carga de la prueba a favor de la parte actora en el juicio, en la que los profesionales médicosanitarios o la institución hospitalaria les corresponde acreditar su debida diligencia en la atención médica del paciente que sufrió el referido evento dañoso, en atención a los 
principios de facilidad y proximidad probatoria, sin embargo el daño y el nexo causal deberá ser acreditado por el paciente.

La razón principal para optar por esta incidencia en las reglas estrictas de la carga de la prueba proviene de las circunstancias particulares en las que se desarrolla un caso de atención médica; por lo general, el conocimiento científico/técnico y las pruebas pertinentes para acreditar la debida diligencia o desacreditar la supuesta culpa o violación de un deber de cuidado las detentan los profesionales médico-sanitarios o las instituciones hospitalaria, por lo cual exigir de una manera irrestricta que sea la parte actora la que demuestre por sí sola y sin lugar a dudas la negligencia en la atención médica podría provocar lo que en la doctrina se denomina como una "carga probatoria diabólica".

Es por ello que la Suprema Corte acude a la concepción de la reinversión de la carga de la prueba, aclarando que no se trata de una inversión formal de las reglas establecidas en el Código de Procedimientos Civiles para el Distrito Federal (en particular, las previstas en los artículos 281 y 282, mediante la cual se obligaría a los demandados a probar desde un inicio que no se actualizaron todos los elementos de la acción de responsabilidad civil (daño, culpa y relación causal), dado que ello iría en contra de la propia ley y de la caracterización de la responsabilidad civil extracontractual derivada de la atención médica como una de carácter subjetivo.

Tal como se determinó en la contradicción de tesis 93/2011, a la parte actora le corresponde acreditar los elementos de daño y nexo causal. Por lo tanto, ambas partes deben de participar activamente en el proceso: la actora, para acreditar la existencia de daño y de relación causal; mientras que la demandada es a la que le corresponde probar que actuó de manera diligente en el acto médico conforme a la lex artis ad hoc. Sólo en caso de que no se acredite la debida diligencia y se haya comprobado concomitantemente la concurrencia de un daño y de una relación causal en relación con ese actuar doloso, entonces recaerá una condena por responsabilidad civil e incluso penal si ocurrieron lesiones.

Lo que se busca con esta denominada reversión de la carga de la prueba motivada por los principios de proximidad y facilidad probatoria en el ámbito médico-sanitario, es que ambas partes en el juicio participen activamente en el proceso y que aporten los elementos 
Revista Eletrônica de Direito Processual - REDP.

Rio de Janeiro. Ano 13. Volume 20. Número 3. Setembro a Dezembro de 2019

Periódico Quadrimestral da Pós-Graduação Stricto Sensu em Direito Processual da UERJ

Patrono: José Carlos Barbosa Moreira (in mem.). ISSN 1982-7636. pp. 75-101

www.redp.uerj.br

de convicción necesarios para que el juzgador pueda llegar a la verdad y estudiar si se acreditan o no los elementos de la acción.

Es atendible el criterio contenido en la tesis aislada número: I.4o.C.330 C (9a.), emitida por el Cuarto Tribunal Colegiado en Materia Civil del Primer Circuito, visible en el Semanario Judicial de la Federación, Libro IV, Enero de 2012, Tomo 5, Décima Época, Página: 4606, de rubro: “RESPONSABILIDAD CIVIL MÉDICA. LA CARGA PROBATORIA DEL ACTOR PUEDE SATISFACERSE TAMBIÉN MEDIANTE INDICIOS OBTENIDOS A PARTIR DE LAS PRUEBAS APORTADAS POR EL DEMANDADO." 22

El actor que afirma que se generó el daño por el médico, debe acreditar la afectación y la culpa del profesional, así como el nexo causal entre ambas. Sin dejar de reconocer la carga probatoria del demandante, y la consecuencia desfavorable que para éste producirá la insuficiencia probatoria, las pruebas no necesariamente habrán de ser aportadas por el actor, ya que es posible que la falta de diligencia se predique al hilo de hechos aducidos por el demandado o que a la vista del desarrollo del proceso, la infiera finalmente el Juez como lógica explicación del resultado, con mecanismos como la presunción judicial, la regla res ipsa loquitur, la prueba prima facie o la culpa virtual, que se han utilizado como referentes decisorios por la doctrina y la jurisprudencia por ésta examinada. Nada obsta para utilizar esos mecanismos en un caso de responsabilidad civil médica, dada la existencia de las presunciones como medio de confirmación y del criterio de valoración probatoria conjunta, sujeta a las reglas de la lógica y de la experiencia, en términos de los artículos 379, 380 y 402 del Código de Procedimientos Civiles para el Distrito Federal. Por ende, aunque existirán pruebas idóneas, según el caso concreto, para acreditar el daño derivado de responsabilidad médica, como la pericial en la específica rama involucrada, nada impide que, en ausencia de esas probanzas, pueda presumirse la culpa del profesional de la medicina, e inclusive el daño mismo y el nexo causal, lo cual dependerá de las circunstancias particulares que habrán de apreciarse bajo la orientación del sistema indicado. Al hacerlo así, no se releva de la carga probatoria al reclamante, aunque sí habrán de tomarse en cuenta los elementos probatorios existentes en el procedimiento, con

22

https://sjf.scjn.gob.mx/sjfsist/paginas/DetalleGeneralV2.aspx?ID=160353\&Clase=DetalleTesisBL\&Semanar $\underline{\mathrm{io}=0}$ 
Rio de Janeiro. Ano 13. Volume 20. Número 3. Setembro a Dezembro de 2019

Periódico Quadrimestral da Pós-Graduação Stricto Sensu em Direito Processual da UERJ

Patrono: José Carlos Barbosa Moreira (in mem.). ISSN 1982-7636. pp. 75-101

www.redp.uerj.br

independencia de que su aportación provenga del demandado, pues serán parte del material confirmatorio, en virtud del principio de adquisición procesal, en su vertiente probatoria, y a pesar de que se trate de meros indicios, dado que será la apreciación judicial la que conducirá a conferirles mayor o menor calidad indiciaria. Tal forma de ponderación probatoria de los indicios, referida al caso específico de la responsabilidad civil médica, es coincidente con la caracterización que, de manera general, corresponde a la denominada prueba indirecta, presuncional o indiciaria. De esa manera, la valoración conjunta de indicios, orientada por las reglas explicadas por la doctrina y jurisprudencia, determinará si es o no posible otorgar valor probatorio pleno a los indicios que estén involucrados en cada caso de responsabilidad civil médica, para acreditar la culpa, principalmente, pero también el daño y el nexo causal, eventualmente. En todo caso, acreditados esos elementos mediante la presunción obtenida a partir de indicios, corresponderá al demandado probar en contrario, ya sea que el daño en modo alguno se produjo, que el origen del mismo no fue la conducta del profesional de la medicina o que éste actuó con la máxima diligencia u obtuvo el resultado, según se trate de obligación de medios o de resultados.

\section{IV.- LA CARGa de LA PRUEBA EN CASOS DE CIRUGía PLÁSTICA Y RECONSTRUCTIVA}

Por regla general, la obligación del profesional de la medicina es de medios y no de resultados. La primera clase de obligaciones supone que el profesionista no se obliga al logro de un concreto resultado, sino al despliegue de una conducta diligente, cuya apreciación está en función de la denominada Lex artis ad hoc. En tal caso, la falta de diligencia y la negligencia del profesional médico, son las que habrán de probarse. En cambio, algunas obligaciones de resultados son las cirugías plásticas estéticas. Sin embargo, la diferencia entre ambas modalidades no aparece en ocasiones muy clara, sobre todo a partir de la asunción del derecho a la salud como bienestar en sus aspectos psíquicos y social, y no solo físico, o de aquellas intervenciones preventivas en las que se actúa a partir de las indicaciones médicas dirigidas a evitar riesgos para la salud o integridad del paciente. De este modo, que la jurisprudencia moderna ha venido a distinguir entre aquellos supuestos en que una actuación profesional trata de curar o mejorar a un paciente de sus dolencias (medicina 
Rio de Janeiro. Ano 13. Volume 20. Número 3. Setembro a Dezembro de 2019

Periódico Quadrimestral da Pós-Graduação Stricto Sensu em Direito Processual da UERJ

Patrono: José Carlos Barbosa Moreira (in mem.). ISSN 1982-7636. pp. 75-101

www.redp.uerj.br

curativa) de aquellos otros supuestos en los que se acude en condiciones de normalidad de salud, con el fin de obtener algún resultado que voluntariamente se quiere conseguir para lograr un aspecto físico más favorecido o evitar la procreación (medicina voluntaria). ${ }^{23}$

El artículo 2615 del Código Civil Federal dispone que el que preste sus servicios profesionales será responsable por impericia, negligencia y dolo, sin perjuicio de las penas que merezca por la comisión de un delito. Si se produce un daño por imprudencia, inadvertencia, falta de atención o cuidado o impericia surge la obligación para los profesionistas de restituir o reparar los daños y perjuicios causados a sus pacientes, debiéndose entender por daño. El deterioro, pérdida o menoscabo sufrido por la falta de cumplimiento de una obligación y por perjuicio, la privación de cualquier ganancia lícita que se obtenga con el incumplimiento de la obligación.

En la medicina estética, el paciente elige por voluntad propia a un médico cirujano plástico para que le realice un procedimiento quirúrgico (obligación de hacer), en el cual la motivación principal del acuerdo de voluntades por parte del paciente es un resultado satisfactorio, de otra manera lógicamente no se sometería a la actuación médica. De tal suerte, que en este tipo de atenciones, la relación médico-paciente adquiere particular relevancia, pues será menester tener en cuenta las características del acto de petición de la atención médica.

En estos casos, la exigencia es de mayor rigor por cuanto hace al deber de información (de forma exhaustiva) sobre las características de la intervención, el resultado perseguido, incluso la posibilidad de que no se logre el resultado esperado. Asimismo, dada la naturaleza y la finalidad que dan origen a este tipo de intervenciones, se requiere la mayor de las diligencias y pericia en la prestación del servicio. Es decir, el profesional de la Medicina deberá acreditar el empleo de los medios y la esmerada diligencia y cuidado durante la atención otorgada, para alcanzar el fin pretendido.

Como se trata de medicina de satisfacción o voluntaria, la necesidad del consentimiento por parte del paciente se vuelve primordial, formando parte de los deberes

\footnotetext{
${ }^{23}$ Gómez Rufián, Luis, Cirugía estética y responsabilidad civil. Análisis sistemático de una compleja jurisprudencia. file:///C:/Users/cgomez.SALUD/Documents/cirug\%C3\%ADa\%20est\%C3\%A9tica_archivos/6440-16704-1PB.pdf
} 
de diligencia del profesional de la Medicina, por ello la información al paciente debe ser más completa, pues lo característico en la Cirugía Estética es que el riesgo de fracaso se asume de modo mucho más libre y espontáneo por el paciente, para ello no podrá dejarse de observar la calidad de información que se le brinde, lo que implica la mayor responsabilidad del profesional sanitario cuando el fracaso deriva de riesgos probables sobre los que no se informó al paciente.

El consentimiento informado comprende dos elementos básicos: la información al paciente y la participación de éste en la toma de decisiones. La información debe ser exhaustiva, objetiva, veraz, completa y asequible, debiendo comprender las posibilidades de fracaso de la intervención, es decir, el pronóstico sobre la probabilidad del resultado, y también cualesquiera secuelas, riesgos, complicaciones o resultados adversos que se puedan producir, de tal forma que ante el conocimiento de los mismos, el paciente pueda sustraerse a una intervención innecesaria, prescindible, o de necesidad relativa.

Por cuanto hace a la cirugía estética, el Reglamento de la Ley General de Salud en Materia de Prestación de Servicios de Atención Médica ${ }^{24}$ establece en su artículo 95 Bis 1, qué se entiende por cirugía estética o cosmética: Es el procedimiento quirúrgico que se realiza para cambiar o corregir el contorno o forma de diferentes zonas o regiones de la cara y del cuerpo, con el propósito de modificar la apariencia física de las personas con fines estéticos. De igual forma el artículo 95 Bis 4 del citado Reglamento, señala que únicamente podrán realizar procedimientos de cirugía estética o cosmética, los médicos con título profesional y cédula de especialidad, otorgada por una autoridad competente, en una rama quirúrgica de la Medicina, en términos de los artículos 78 y 81 de la Ley. Los médicos en formación podrán realizar dichos procedimientos, acompañados y supervisados por un especialista en la materia.

A continuación se presentan a dos casos de procesos arbitrales promovidos ante la Comisión Nacional de Arbitraje Médico, en los cuales se analizará la distribución de las cargas probatorias de las partes.

\section{1.- MASTOPEXIA Y ABDOMINOPLASTÍA}

\footnotetext{
${ }^{24}$ http://www.salud.gob.mx/unidades/cdi/nom/compi/rlgsmpsam.html
} 
Se firmó compromiso arbitral entre la paciente y el prestador del servicio médico en el cual ambas partes designaron a la Comisión Nacional de Arbitraje Médico para que resolviera su controversia. Entre las pretensiones de la actora se pactó determinar si el médico (quien se ostentó con un Diploma de Maestro en Cirugía Estética, es decir, no acreditó ser especialista ni contó con certificación alguna) había actuado de conformidad con la Lex Artis en la realización de una mastopexia (cirugía estética que permite la mejora y levantamiento de las mamas caídas) y una abdominoplastía (procedimiento quirúrgico de reconstrucción de la pared abdominal). La paciente de 39 años exigió al médico el reembolso de los gastos erogados y los honorarios que se le habían pagado, los cuales ascendieron a la cantidad de $\$ 180,000$ pesos.

En este caso correspondía al médico demandado acreditar que durante la atención médica que brindó a la actora, cumplió con las debidas obligaciones de seguridad y de medios, mediante la búsqueda del diagnóstico temprano y tratamiento oportunos, a fin de buscar asegurar la correcta atención a la paciente, conforme a las circunstancias concurrentes (lugar, tiempo y modo en que otorgó el servicio de atención).

Máxime, los principios de facilidad y proximidad probatoria, con base en los cuales, la carga de la prueba corresponde a la demandada, por ser quien dispone de los medios de prueba, puede producirla o aportarla al proceso a un menor costo para que pueda ser apreciada y valorada.

En el expediente aportado por el demandado, no se encontró descripción técnica de los procedimientos quirúrgicos realizados a la paciente, incumpliendo lo que establece la Norma Oficial Mexicana NOM-004-SSA3-2012, Del expediente clínico ${ }^{25}$, en virtud de que no realizó nota preoperatoria, como lo señala el numeral 8.5 , el cual deberá contener como mínimo, fecha de la cirugía, diagnóstico, plan quirúrgico, tipo de intervención quirúrgica, riesgo quirúrgico, cuidados y plan terapéutico preoperatorios, pronóstico.

De igual forma, en el expediente médico presentado por el demandado, no se encontró nota postoperatoria, como lo establece la referida Norma, en su numeral 8.8, que deberá ser elaborada por el cirujano que intervino a la paciente al término de la cirugía, la cual constituye un resumen de la operación practicada y la cual deberá contener como

${ }^{25}$ http://dof.gob.mx/nota_detalle popup.php?codigo $=5272787$ 
mínimo y de acuerdo a cada caso: Diagnóstico preoperatorio; Operación planeada; Operación realizada; Diagnóstico postoperatorio; Descripción de la técnica quirúrgica; Plan de manejo y tratamiento postoperatorio inmediato; Pronóstico; y Nombre completo y firma del responsable de la cirugía.

Después del procedimiento quirúrgico, el demandado se abstuvo de vigilar el post operatorio inmediato y mediato que realizó a la paciente a nivel mamario y abdominal. No hay prueba alguna de haberle dado indicaciones y recomendaciones pertinentes para su cuidado en su domicilio, sin embargo consta en el expediente que le indicó un medicamento no apto para la complicación que la paciente presentó, sin haberla evaluado personalmente y sin conocer cómo se encontraba realmente la zona afectada. Sólo le daba indicaciones por medio de Whats-ups, costumbre que por desgracia adoptan muchos médicos, sin tener a la vista a los pacientes. Las copias impresas de los recados intercambiados por el médico y la paciente fueron ofrecidos por ésta última como una prueba documental.

Al sentirse abandonada, la paciente acudió a otro hospital por lo que la parte actora, debía acreditar la calidad de la atención recibida en diverso hospital. El segundo hospital reportó a la paciente con mamas con ptosis grado II, (caída del pecho), mama derecha con herida sub-areolar de 3 centímetros con exposición de grasa, herida en base de la mama aproximadamente 3.5 centímetros, a través de la cual se observó el implante expuesto y líquido moderado no fétido con hiperemia.

Los procedimientos ejecutados por el demandado no estuvieron indicados ni justificados, por lo tanto, aun cuando a la paciente se le informó de tales complicaciones, éstas no podían ser consideradas como riesgos inherentes, en virtud de que no se justificó el acto quirúrgico.

Al final, la paciente acreditó el daño causado por el demandado con las constancias médicas del segundo hospital. Se le tuvo por probada la asimetría mamaria, es decir, la diferencia en el tamaño de las mamas, la presencia de cicatriz por arriba de surco inframamario, la asimetría en pezones y la pérdida de la circunferencia de los mismos, con hiperemia (aumento de sangre) de la cicatriz de la mama del lado derecho, en la parte central de la misma. Se acreditó plenamente que se produjeron lesiones en la paciente y que el causante directo de dichas lesiones fue el comportamiento lesivo del médico que provocó 
Rio de Janeiro. Ano 13. Volume 20. Número 3. Setembro a Dezembro de 2019

Periódico Quadrimestral da Pós-Graduação Stricto Sensu em Direito Processual da UERJ

Patrono: José Carlos Barbosa Moreira (in mem.). ISSN 1982-7636. pp. 75-101

www.redp.uerj.br

una vulneración a la integridad física de la paciente. Acreditada la mala práctica se condenó al Maestro en Cirugía estética al pago de lo reclamado.

Aunado a lo anterior, en el laudo se hizo la siguiente consideración: Los maestros en cirugía estética no cuentan con la pericia exigida por la Ley (conocimientos, habilidades, aptitudes y destrezas) para realizar cirugías plásticas y reconstructivas, al no ser especialistas en la materia y no contar con la certificación necesaria.

La Ley General de Salud en su Artículo 272 Bis $^{26}$, establece:

"Para la realización de cualquier procedimiento médico quirúrgico de especialidad, los profesionales que lo ejerzan requieren de:

I. Cédula de especialista legalmente expedida por las autoridades educativas competentes.

II. Certificado vigente de especialista que acredite capacidad y experiencia en la práctica de los procedimientos y técnicas correspondientes en la materia, de acuerdo a la Lex Artis ad hoc de cada especialidad, expedido por el Consejo de la especialidad según corresponda, de conformidad con el artículo 81 de la presente Ley.

En este caso, ante una demanda en la que se alegó la existencia de un daño motivado por una atención médica fallida, al médico le correspondía probar su debida diligencia (el elemento de culpa) en atención a los principios de facilidad y proximidad probatoria y sin embargo con la simple revisión del expediente clínico, exhibido por él mismo, se pudo deducir precisamente la falta de diligencia en su actuación, así como la negligencia e impericia en el manejo de las cirugías practicadas a la paciente. Sin embargo, le correspondió a la actora acreditar el daño causado así como el nexo causal. Con el expediente clínico del segundo hospital la paciente pudo acreditar plenamente el daño que le causó el demandado.

La responsabilidad civil médica consiste en un deber que tiene un médico de reparar los daños y perjuicios ocasionados a su paciente derivado de sus actos, omisiones y errores voluntarios e involuntarios realizados en ejercicio de su profesión. Los requisitos para que se configure dicha responsabilidad civil son los siguientes: una conducta ilícita, un daño por la falta de cumplimiento de una obligación y una relación de causalidad, es decir el nexo o relación de carácter objetivo entre la acción y el resultado. Debe existir un daño (patrimonial,

${ }^{26}$ http://www.salud.gob.mx/unidades/cdi/legis/lgs/LEY_GENERAL_DE_SALUD.pdf 
lesiones o daño moral) y una relación de causalidad, así como el responsable del daño por la conducta causante de la afectación.

\section{2.- CAMBIO DE IMPLANTES}

En el compromiso arbitral se pactó determinar si el Maestro en Cirugía estética había actuado conforme a la Lex Artis al haber pactado un cambio de implante de la pantorrilla izquierda. A la paciente se le habían colocado años atrás, implantes en las rodillas y en virtud de que tenía mucho dolor al caminar, el médico le diagnosticó que era necesario el cambio del implante de la pantorrilla izquierda.

Sin embargo, la paciente de 64 años demandó ante la CONAMED el reembolso del costo de la cirugía que se le practicó y que ascendió a la cantidad de $\$ 48,000$ pesos; toda vez que la demandada no le había colocado un implante nuevo, sino que le dejó el que ya tenía. No mejoró su apariencia. Al momento de presentar la demanda arbitral continuaba con dolores y calambres en los pies.

Durante la etapa de desahogo de pruebas la CONAMED ordenó como prueba para mejor proveer una tomografía contrastada computarizada de ambas piernas, gracias a la cual, se evidenció que la paciente presentaba una desproporcionada asimetría a nivel de las pantorrillas, lo cual se debió a que en la pantorrilla del lado derecho se observaba líquido con contorno irregular, lo anterior por encontrarse mal colocado el implante, con múltiples calcificaciones y aumento de volumen con respecto al lado izquierdo. Es decir, el implante que debió sustituirse era el implante derecho y no el izquierdo. Gracias a esta prueba ordenada para mejor proveer se puso en evidencia que el demandado simuló haber colocado un nuevo implante en la pantorrilla izquierda, exhibiendo incluso una etiqueta de un implante. Sin embargo en la etiqueta se leía: implante izquierdo de mama ( sic); lo cual puso de manifiesto el dolo bajo el cual actuó el médico, quien se ostentó con un Diploma de Maestro en cirugía estética, sin contar con autorización para realizar cirugías, al carecer de la especialidad en cirugía plástica y certificación exigidas legalmente.

En el expediente clínico exhibido por el propio médico que sirvió como prueba en su contra, se leía: "se sacó el implante, se revisó su integridad, se bañó en antibiótico y ese mismo implante se volvió a colocar", es decir, el médico nunca cambió el implante. Al haber 
efectuado un retiro injustificado del implante de pantorrilla izquierda y colocarlo nuevamente, sin haberlo cambiado tal y como se había programado y comprometido con la paciente, fue prueba suficiente para tener por acreditada una conducta negligente y dolosa del médico.

Fue procedente por tanto, que la demandada respondiera por el incumplimiento tanto contractual como extracontractual, atendiendo a lo pactado por las partes en el acuerdo arbitral y con fundamento en el artículo 2025 del Código Civil ${ }^{27}$ que refiere: "Hay culpa o negligencia cuando el obligado ejecuta actos contrarios a la conservación de la cosa o deja de ejecutar los que son necesarios para ella." De igual suerte, en concordancia con lo previsto en artículo 35 de la Ley Reglamentaria del artículo $5^{\circ}$ Constitucional relativa al ejercicio de las profesiones en la Ciudad de México, en el presente caso, el laudo fue adverso al médico, y por tanto no tuvo derecho a cobrar honorarios y se le condenó a indemnizar a la paciente por los daños y perjuicios que se le ocasionaron.

En el presente caso, con las pruebas ofrecidas únicamente por las partes no existían elementos suficientes para conocer la verdad. Fue fundamental ordenar una prueba para mejor proveer que consistió en la tomografía actualizada, con la que se pudo descubrir el estado que guardaban los implantes de la paciente. Con esta prueba adminiculada con el expediente exhibido por el médico, se demostró que no solamente el médico fue negligente, sino que actuó con dolo al simular haber cambiado un implante, cuando en realidad no lo hizo. Pese a que Ovalle Favela señala que ordenar de oficio la práctica de pruebas es una reminiscencia de una muy arraigada tradición inquisitorial ${ }^{28}$ la tendencia de la CONAMED se acerca al pensamiento de Michele Taruffo, citado por el mismo Ovalle Favela, quien sostiene que la prueba tiene por objeto la determinación de la verdad de los hechos, con características de relatividad y razonabilidad, y constituye un método análogo al utilizado para el control de las teorías científicas. ${ }^{29}$

No hay que olvidar que además se trató de un médico, quien ostentándose con un título de maestría, ilícitamente realizó una cirugía plástica, sin estar autorizado para ello, al no contar con la especialidad en cirugía plástica y reconstructiva ni con la certificación

\footnotetext{
${ }^{27}$ https://www.oas.org/dil/esp/C\%C3\%B3digo\%20Civil\%20Federal\%20Mexico.pdf

${ }^{28}$ Ovalle Favela, José, op.cit. p.336

${ }^{29}$ Ibidem,p.339
} 
Revista Eletrônica de Direito Processual - REDP.

Rio de Janeiro. Ano 13. Volume 20. Número 3. Setembro a Dezembro de 2019

Periódico Quadrimestral da Pós-Graduação Stricto Sensu em Direito Processual da UERJ

Patrono: José Carlos Barbosa Moreira (in mem.). ISSN 1982-7636. pp. 75-101

www.redp.uerj.br

correspondiente $^{30}$ violentando con ello el derecho humano de la paciente a la protección de su salud.

\section{REFERENCIAS:}

DEVIS ECHANDÍA, Hernando, Compendio de la prueba judicial, Argentina, RubinzalCulzoni Editores, 2007.

DÍAZ-RESTREPO, Juan Carlos, La carga dinámica de la prueba como modalidad de carga probatoria aplicada en el ordenamiento jurídico colombiano. Vulneración a la igualdad constitucional. Entramado. Enero.Julio,2016 vol.12, no I. http://www.scielo.org.co/pdf/entra/v12n1/v12n1a14.pdf

GÓMEZ RUFIÁN, Luis, Cirugía estética y responsabilidad civil. Análisis sistemático de una compleja jurisprudencia. file:///C:/Users/cgomez.SALUD/Documents/cirug\%C3\%ADa\%20est\%C3\%A9tica_a rchivos/6440-16704-1-PB.pdf

GRAYEB CERVANTES, Antonio, El derecho humano a la salud, la representación aparente y la responsabilidad en la prestación de servicios médicos particulares. México, Revista Conamed, Volúmen 24, Número 1, Enero.marzo, 2019.

LÓPEZ OLIVA, José, La carga de la prueba en procedimientos de cirugía plástica en Colombia, Barranquilla,Universidad Libre Seccional, Advocatus, Volúmen 13,No. 26: 41-58,2016.

\footnotetext{
${ }^{30}$ Artículo 81 de la Ley General de Salud.- El Comité Normativo Nacional de Consejos de Especialidades Médicas tendrá la naturaleza de organismo auxiliar de la Administración Pública Federal a efecto de supervisar el entrenamiento, habilidades, destrezas y calificación de la pericia que se requiere para la certificación y recertificación de la misma en las diferentes especialidades de la medicina reconocidas por el Comité y en las instituciones de salud oficialmente reconocidas ante las autoridades correspondientes. Los Consejos de Especialidades Médicas que tengan la declaratoria de idoneidad y que estén reconocidos por el Comité Normativo Nacional de Consejos de Especialidades Médicas, constituido por la Academia Nacional de Medicina de México, la Academia Mexicana de Cirugía y los Consejos de Especialidad miembros, están facultados para expedir certificados de su respectiva especialidad médica. Para la expedición de la cédula de médico especialista, las autoridades educativas competentes solicitarán la opinión del Comité Normativo Nacional de Consejos de Especialidades. Médicas.https://cmcper.org.mx/index.php/directorio-ymapa/medicos
} 
OVALlE FAVELA, José, Teoría General del Proceso, México, Oxford University Press,

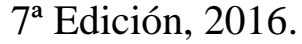

PARRA QUIJANO, Jairo, Manual de derecho probatorio, Bogotá, Ediciones Librería del Profesional, 1986, p.3 y Racionalidad e Ideología en las pruebas de oficio, Temis, Bogotá, 2004.

PÉREZ RESTREPO, Juliana, La carga dinámica de la prueba en la responsabilidad administrativa por la actividad médica-decaimiento de su aplicabilidad. Universidad de Antioquía, Medellín. Colombia, Vol. LXVIII.No.152,diciembre 2011, http://bibliotecadigital.udea.edu.co/bitstream/10495/2374/1/PerezJuliana_2011_Carg aResponsabilidadAdministrativa.pdf

PEYRANO, Jorge Walter, et al. Cargas probatorias dinámicas, Argentina, RubinzalCulzoni Editores, 2008.

ROSENBERG, Leo, La carga de la prueba, Montevideo, B de F, 2002. 